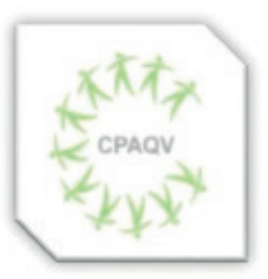

ISSN: 2178-7514
ARTIGO ORIGINAL

\section{PERCEPÇÃO DOS PAIS ACERCA DA VIGILÂNCIA DO DESENVOLVIMENTO INFANTIL EM UM NÚCLEO DE APOIO}

Jorgeane Pedrosa Pantoja ${ }^{1}$; Nayan Leonardo Sousa Lopes²; Matheus Sodré de Araújo ${ }^{3}$; Erica Silva de Souza Matsumura ${ }^{4}$; Katiane da Costa Cunha ${ }^{5}$

Vol. 13 | No. 1| Ano 2021

\title{
RESUMO
}

Objetivo: Analisar a percepção dos pais acerca dos atendimentos no serviço de vigilância do desenvolvimento infantil realizado em um Núcleo de Apoio à Saúde da Família. Método: Estudo qualitativo onde pesquisou-se 9 mães e 1 avó materna que eram responsáveis por crianças em atendimento de Vigilância do Desenvolvimento Infantil. O método da análise de Bardin foi utilizado para a análise de dados. A faixa etária dos participantes foi de 19 a 5 anos e o estado conjugal varia entre solteira, viúva e casada. Resultados: Permitiram inferir que o serviço alcançou efeitos positivos com os pais, o conceito de saúde é amplo e vai além dos aspectos fisiológicos, envolvendo o contexto familiar, social e outros mais, e a utilização do serviço é utilizada não somente para tratamento, mas também para prevenção. Conclusão: A produção desta pesquisa ofereceu informações essenciais sob a ótica dos usuários acerca do serviço que vem sendo realizado no Núcleo de Apoio à Saúde da Família. Diante das percepções verificou-se a amplitude que o serviço tem alcançado nos cuidados à primeira infância. Ao entrelaçar os usuários, representado pelos pais e crianças, ao serviço de atenção primária, busca-se estimulá-los a buscarem por maior envolvimento nas políticas públicas resultando assim em um usuário mais autônomo no processo saúde.

Palavras-chave: Atenção primária à saúde. Desenvolvimento infantil. Relações profissional-família.

\section{ABSTRACT}

Objective: To analyze the parents' perception about the attendance at the child development surveillance service performed at a Family Health Support Center. Method: Qualitative study where 9 mothers and 1 maternal grandmother were researched, who were responsible for children in child development surveillance. The method of Bardin's analysis was used for data analysis. The age range of the participants was 19 to 5 years and the marital status varies between single, widowed and married. Results: Allowed to infer that the service achieved positive effects with the parents, the concept of health is broad and goes beyond physiological aspects, involving the family, social and other contexts, and the use of the service is used not only for treatment but also for prevention. Conclusion: The production of this research offered essential information from the perspective of users about the service that has been carried out at the Family Health Support Center. In view of the perceptions, it was verified the breadth that the service has achieved in early childhood care. By intertwining users, represented by parents and children, with the primary care service, we seek to encourage them to seek greater involvement in public policies, thus resulting in a more autonomous user in the health process.

Keywords: Primary health care. Child development. Professional-family relations.

1. Universidade do Estado do Pará (UEPA), Belém, Pará, Brasil

2. Universidade da Amazônia, Belém, Pará, Brasil

3. Universidade do Estado do Pará (UEPA), Marabá, PA, Brasil

4.Fisioterapeuta. Doutoranda em Biologia Parasitária na Amazônia (BPA), Universidade do Estado do Pará (UEPA)

5.Fisioterapeuta. Pós- Doutora em Psicologia Teoria e Pesquisa do Comportamento, Universidade do Estado do Pará (UEPA)

Autor de correspondência

Erica Silva de Souza Matsumura

erica.s.souza@terra.com.br

DOI: $10.36692 / v 13 n 1-21$ 


\section{INTRODUÇÃO}

A Política Nacional de Atenção Integral à Saúde da Criança (PNAISC) tem a finalidade de determinar as orientações e qualificações das ações e serviços de saúde da criança no Brasil, garantindo o direito à vida e à saúde, a fim de permitir o pleno desenvolvimento na infância, reduzir os riscos de adoecimento e prevenir doenças crônicas na vida adulta. Nesse sentido, um eixo estratégico dessa política é a promoção e acompanhamento do desenvolvimento integral, que consiste na vigilância e na estimulação do crescimento e desenvolvimento da criança oferecida pela atenção básica de saúde e orientada pela Caderneta de Saúde da Criança (CSC), além de apoiar as famílias com ações que visam fortalecer o vínculo profissional-família ${ }^{1}$.

O desenvolvimento da criança é um indicador de saúde que tem influência de fatores biológicos e ambientais e é avaliado por meio da observação de atividades motoras, da linguagem, da comunicação, da memorização e da aprendizagem. Esse processo gera autoconfiança, autoestima e boa capacidade de relacionamento social, assim como seu estímulo pode possibilitar que o indivíduo seja um adulto bem adaptado socialmente ${ }^{2}$.

A vigilância do desenvolvimento da criança é um acompanhamento continuado de ações que promovem o potencial desenvolvimento da criança e detectam problemas. Nos primeiros anos de vida possui alta importância, pois o tecido nervoso tem um maior crescimento e amadurecimento nessa etapa, estando mais susceptível aos agravos, e devido a essa grande plasticidade, a criança tem uma melhor resposta aos estímulos recebidos do meio ambiente e intervenções. Por isso, é fundamental que nesse período ocorra participação dos profissionais de saúde, família e comunidade ${ }^{2}$.

O profissional da atenção básica pode realizar a vigilância do desenvolvimento da criança por meio do uso de brinquedos e objetos que geram respostas reflexas, em um ambiente tranquilo, com a criança em boas condições emocionais e de saúde. Também é importante escutar a opinião dos pais/cuidadores sobre o desenvolvimento e verificar a interação da mãe/ cuidador com a criança (vínculo), a forma como segura a criança, a existência de contato visual e verbal com afeto, os cuidados com a higiene da criança, pois são um importante fator de proteção para o desenvolvimento humano ${ }^{2}$.

A relação do contexto familiar com o desenvolvimento da criança é de fundamental importância. É nesse espaço que ocorrem as primeiras relações da criança e que são importantes para o desenvolvimento psicossocial, uma vez que os laços afetivos que são construídos irão influenciar o desenvolvimento saudável da criança e determinar modos de interações positivas ${ }^{3}$.

A atenção à saúde da criança vem sofrendo mudanças estruturais e organizacionais nos serviços de saúde influenciadas por diferentes contextos de políticas públicas de saúde, os 
quais estão sempre em evolução. A adoção de estratégias visando a promoção de saúde infantil é verificada na coexistência de diversos modelos de atenção primária à saúde (APS) que geram diferentes formas de cuidados à criança. Contudo, não há garantia da integralidade da atenção à saúde infantil pois ainda é um processo em fase de construção e não há um alcance da resolutividade necessária a um atendimento de APS, descaracterizando a atenção básica como um acesso de primeiro contato do sistema. Ademais, em relação as orientações familiares, mesmo ocorrendo maior interação das equipes com a família, ainda não se alcançou um patamar desejado nessa orientação, sendo necessário refletir sobre a forma de estruturação da atenção infantil na APS, uma vez que a integração e a articulação com a família são importantes para o cuidado integral das crianças ${ }^{4}$.

Neste sentido, a partir das vivências em Núcleo Apoio à Saúde da Família (NASF) Águas Lindas, Ananindeua (PA), no Serviço de Vigilância do Desenvolvimento Infantil, surge o seguinte questionamento para essa pesquisa: como se dá a participação dos pais nos cuidados com o desenvolvimento dos seus filhos e quais as impressões que eles têm a respeito do serviço? Por isso, o presente estudo tem o objetivo de analisar a percepção dos pais acerca dos atendimentos no serviço de vigilância do desenvolvimento infantil realizado em um Núcleo de Apoio à Saúde da Família.

\section{MÉTODO}

Pesquisa de natureza qualitativa do tipo exploratória, realizada em Ananindeua, Pará, no NASF Águas Lindas, com 9 mães e 1 avó materna responsáveis por crianças em atendimento de Vigilância do Desenvolvimento Infantil.

O serviço de Vigilância do Desenvolvimento Infantil pesquisado funciona por meio do atendimento agendado, no qual as marcações são feitas na "Sala de Espera do Teste do Olhinho" com os Agentes Comunitários de Saúde (ACS) e de outros profissionais das ESF ou por meio de encaminhamento dos profissionais do NASF. Os atendimentos são realizados duas vezes por semana (segundas e sextas-feiras pelo período matutino) e são agendados dez atendimentos. No entanto, ocorre ausência com e sem justificativas, remarcações, entre outros, gerando a média de atendimento/dia em torno de 5 usuários. O acompanhamento ocorre mensalmente para as crianças até os dozes meses de idade, após esse período passa a ser a cada três meses e ao completar dois anos de idade passar a ser anual até os sete anos de idade. $\mathrm{O}$ atendimento realizado no serviço envolve a avaliação física dos principais marcos do desenvolvimento infantil, baseado em protocolo científico validado, como o protocolo de Desenvolvimento Neurológico Infantil proposto por Coelho em 1999, nas ações primárias em saúde, bem como observações do contexto sociocultural da criança. 
Os critérios de inclusão foram: pais e/ou responsáveis das crianças que possuíam tempo de acompanhamento maior que 3 (três) meses no Serviço de Vigilância do Desenvolvimento Infantil do NASF Águas Lindas com participação assídua durante os atendimentos e após o contato inicial e, que depois da apresentação da proposta da pesquisa e dos esclarecimentos éticos, aceitaram participar e assinaram o TCLE.

A amostra se justifica pela média de atendimentos que seria realizado semanalmente, no entanto, em decorrência das ausências no serviço e evasões, eventualmente não se alcança essa média e por considerar que o número da amostra de 10 (dez) participantes selecionados de acordo com os critérios de inclusão, já citados, possibilite um panorama do objeto de estudo da pesquisa.

Os dados do estudo foram obtidos por meio de entrevista para conhecer o perfil socioeconômico e cultural das famílias, em que se desenvolveu uma ferramenta de escuta ao usuário, caracterizado como um questionário semiestruturado elaborado a partir das vivências durante as práticas de Treinamento em Serviço da Residência Multiprofissional em Saúde no NASF. O questionário apresentou 3 (três) perguntas subjetivas e 1 (uma) pergunta objetiva relacionadas ao serviço, possibilitando ao usuário expor seu "olhar" sobre o serviço, bem como, compartilhar as dificuldades enfrentadas e buscou "escutar" sugestões para a melhoria do serviço prestado a comunidade.
No que confere aos esclarecimentos éticos, a pesquisa foi desenvolvida conforme as Normas preconizadas pela Resolução 466/12 de 12 de Dezembro de 2012 (BRASIL, 2012) quanto à não maleficência e a beneficência, bem como a coleta de dados iniciada somente após a garantia da assinatura de todos participantes no Termo de Consentimento Livre e Esclarecido (TCLE).

No que se refere à análise dos dados, optou-se em utilizar o método da análise de conteúdo de Laurence Bardin, organizada em 3 etapas: pré-análise, exploração do material e categorização do comportamento verbal obtido a partir das respostas dos participantes, de modo a respeitar as diferenças e semelhanças. ${ }^{5}$

O projeto de pesquisa foi submetido ao Comitê de Ética em Pesquisa com Humanos do Centro de Ciências Biológicas e da Saúde da UEPA sob o Certificado de Apresentação para Apreciação Ética (CAAE) número: 55768016.8.0000.5168, sendo autorizada sob o parecer de número 1.741.732.

Para a preservação de identidade, substituiu-se os nomes dos participantes por codinomes de pedras preciosas, sendo que os dados de cada participante serão resguardados pela pesquisadora pelo período de 5 (cinco) anos.

\section{RESULTADOS}

Características dos participantes

A pesquisa ficou composta por 10 (dez) pessoas do sexo feminino, sendo 9 (nove) com 
vínculo materno e 1 (uma) avó materna. Durante a coleta dos dados da pesquisa de campo, 2 (duas) mães foram acompanhadas pelos pais das crianças, no entanto, eles não participaram da entrevista por acompanharem as crianças esporadicamente no serviço e por acreditarem que a genitoras estariam mais preparadas para responderem as perguntas. É importante destacar que os pais ainda chegavam até o serviço de acompanhamento com frequentes preocupações e dúvidas não sanadas relacionadas as etapas desenvolvimento infantil, principalmente, no que confere aos cuidados prestados à criança nos primeiros meses de vida, evidenciando que a figura materna assume as responsabilidades frente aos cuidados prestados com os filhos no ambiente familiar.

A tabela 1 mostra as principais características das participantes da pesquisa.

Tabela 1: caracterização das participantes

\begin{tabular}{|c|c|c|c|c|c|c|}
\hline Participante & $\begin{array}{l}\text { Idade } \\
\text { (anos) }\end{array}$ & Estado Civil & Escolaridade & Profissão & Religião & $\begin{array}{l}N^{\circ} \text { de } \\
\text { filhos }\end{array}$ \\
\hline Ágata & 51 & Solteira & $\begin{array}{l}\text { Ensino } \\
\text { Fundamental } \\
\text { Incompleto }\end{array}$ & Do lar & Católica & 2 \\
\hline Amazonita & 19 & "amigada" & $\begin{array}{l}\text { Ensino } \\
\text { Fundamental } \\
\text { Incompleto }\end{array}$ & Estudante & Evangélica & 1 \\
\hline Âmbar & 23 & Casada & Ensino Médio & Do lar & Católica & 1 \\
\hline Topázio & 36 & Casada & Ensino Médio & Do lar & Católica & 4 \\
\hline Ônix & 29 & Casada & $\begin{array}{l}\text { Ensino Médio } \\
\text { Incompleto }\end{array}$ & Do lar & Evangélica & 2 \\
\hline Pérola & 21 & "União estável" & Ensino Médio & Do lar & Evangélica & 1 \\
\hline Jade & 34 & Casada & Ensino Superior & Contadora & Evangélica & 3 \\
\hline Turquesa & 26 & Casada & Ensino Médio & Do lar & Evangélica & 2 \\
\hline Esmeralda & 32 & Casada & Ensino Superior & $\begin{array}{l}\text { Assistente } \\
\text { Social }\end{array}$ & Protestante & 1 \\
\hline Gramada & 27 & Solteira & $\begin{array}{l}\text { Ensino } \\
\text { Fundamental } \\
\text { Incompleto }\end{array}$ & Do lar & Católica & 2 \\
\hline
\end{tabular}

Fonte: Pesquisa de Campo.

Segundo a tabela 1 , as participantes da pesquisa foram adultas na faixa etária de 19 a 51 anos, com estado civil majoritariamente casado, sendo que duas participantes definiram sua relação com outras nomeações e apenas uma estava solteira. No que se refere à escolaridade das participantes, verifica-se variação entre os níveis de ensino Fundamental até o Superior, com predomínio do Médio. Em relação a profissão, a ocupação do lar é prevalente, assim como a religião Evangélica é a predominante. O número de filhos variou entre 1 a 4, contudo a maioria possuía de 1 a 2 filhos.

A tabela 2 apresenta a organização socioeconômica das participantes entrevistadas. 
Tabela 2: caracterização socioeconômica

\begin{tabular}{ccccc}
\hline Participante & $\begin{array}{c}\text { Recebe } \\
\text { Benefício }\end{array}$ & $\begin{array}{c}\text { Renda Familiar } \\
\text { (salário mínimo) }\end{array}$ & $\begin{array}{c}\text { Situação de } \\
\text { Moradia }\end{array}$ & $\begin{array}{c}\text { No de membros da } \\
\text { família }\end{array}$ \\
\hline $\begin{array}{c}\text { Ágata } \\
\text { Amazonita }\end{array}$ & Sim & $\sim 1$ & Casa própria & 3 \\
Âmbar & Sim & $\sim 1$ & $\begin{array}{c}\text { Casa Cedida } \\
\text { Casa própria }\end{array}$ & 3 \\
Topázio & Sim & $\begin{array}{c}\text { Não soube } \\
\text { informar }\end{array}$ & Casa própria & 7 \\
Onix & Sim & 2 & Casa própria & 5 \\
Pérola & Não & 4 & Casa própria & 6 \\
Jade & Sim & 2 & Casa própria & 5 \\
Turquesa & Sim & Atualmente sem & Casa própria & 4 \\
Esmeralda & Não & 1 & Casa própria & 3 \\
Gramada & Não & 1 & Casa própria & 3 \\
\hline
\end{tabular}

Fonte: Pesquisa de Campo

Conforme a tabela 2, os benefícios Sobre a situação de moradia, há predomínio de sociais prevaleceram entre as famílias, com casas próprias, com uma casa cedida. Enquanto destaque para o Bolsa Família e o benefício de os membros da família variam de 3 a 7 pessoas. Prestação Continuada. A renda familiar variou de A tabela 3 evidencia os temas que foram aproximadamente 1 a 4 salários mínimos, com utilizados para análise dos dados. prevalência de renda menor ou igual a 1 salário.

Tabela 3: apresentação dos temas para análise dos dados.

\begin{tabular}{|c|c|}
\hline Temas & Objetivos \\
\hline $\begin{array}{l}\text { A percepção dos pais acerca das etapas } \\
\text { do desenvolvimento infantil }\end{array}$ & $\begin{array}{l}\text { Dissertar a respeito do envolvimento dos } \\
\text { pais com os cuidados prestados para } \\
\text { favorecer o processo de } \\
\text { desenvolvimento dos seus filhos. }\end{array}$ \\
\hline $\begin{array}{l}\text { As repercussões dos atendimentos no } \\
\text { cotidiano dos pais }\end{array}$ & $\begin{array}{l}\text { Abordar as mudanças introduzidas no } \\
\text { ambiente familiar, bem como, no } \\
\text { comportamento das famílias a partir das } \\
\text { orientações recebidas no serviço }\end{array}$ \\
\hline $\begin{array}{l}\text { Significados e dificuldades atribuídos ao } \\
\text { serviço de vigilância do Desenvolvimento } \\
\text { Infantil no NASF Águas Lindas. }\end{array}$ & $\begin{array}{l}\text { Investigar as expectativas que não } \\
\text { foram correspondidas pelo serviço, às } \\
\text { dificuldades enfrentam no serviço e os } \\
\text { motivos/dificuldades que possa } \\
\text { ocasionar as evasões nos atendimentos }\end{array}$ \\
\hline
\end{tabular}

Desta forma, de acordo com a tabela 3 , as falas dos participantes foram categorizadas em 3 temáticas: a percepção dos pais acerca das etapas do desenvolvimento infantil; as repercussões dos atendimentos no cotidiano dos pais; significados e dificuldades atribuídos ao serviço de vigilância do Desenvolvimento Infantil no NASF Águas Lindas. 
A percepção dos pais acerca das etapas do desenvolvimento infantil para os pais, em especial os de primeira viagem, as dúvidas relacionadas, por exemplo, ao marco do desenvolvimento, faziam com que eles realizassem comparações do desenvolvimento dos seus filhos com $\mathrm{O}$ desenvolvimento dos filhos de parentes e amigos. Despertando assim, sentimentos como de angústia frente a situações em que a criança não apresentava o desenvolvimento compatível com o parâmetro comparado:

"Eu me preocupo com ela. A saúde dela é o mais importante para mim. Por isso sempre venho aqui e quando falto, tento remarcar" (Esmeralda).

"Quando a gente falta, fico agoniada. Venho aqui remarcar porque sei que é importante!" (Amazonita).

"Ela ficava muito molezinha e eu já estava preocupada porque todo mundo estava dizendo que não era normal" (Pérola).

"Desconhecia esses detalhes que tinha que observar nele. Não sabia que cada mês ele fazia coisa nova, depois que comecei a vir aqui fui observando, porque eles vão me explicando" (Pérola).

Ainda se constatou que os pais chegavam até o serviço com dúvidas em relação aos cuidados diários que deveriam prestar aos seus filhos. Como alguns relatos, as dúvidas relacionadas como segurar o bebê, causando insegurança no momento de carregá-los, entre outras:

"Como ele foi o meu primeiro filho, não sabia muito do que fazer com ele" (Amazonita).

"Não sabia a forma certa de carregar ela, de colocar ela sentadinha. Tinha medo de fazer alguns movimentos com ela tão pequenina"(Âmbar).

Durante a pesquisa foi possível perceber que no decorrer dos atendimentos foram oportunizados a esses pais os esclarecimentos de suas dúvidas e foram realizados diálogos e orientações num processo continuo, que ocasionou a eles percepções diferenciadas de outros serviços de atenção à criança.

A pesquisa revelou que os participantes percebem as diferenças entre os conceitos de crescimento e desenvolvimento humano subjetivamente, reforçando essa percepção através da observação das diversas formas em que se realizam as abordagens do desenvolvimento infantil pelos profissionais da atenção à saúde da criança:

"Eu vejo que aqui a consulta é diferente. Eles olham tudo que ela passa a fazer cada vez que venho aqui, os movimentos, como ela pega" (-).

Assim sendo, eles percebem mais claramente os objetivos do serviço de acompanhamento, no qual é a prevenção e a continuidade da atenção as habilidades das etapas do desenvolvimento infantil, o que se torna diferenciador da abordagem do processo de crescimento, por vezes, objeto de foco outros profissionais da saúde.

Durante a pesquisa, ao suscitar reflexões sobre as informações e esclarecimentos que os participantes têm recebido direcionados ao desenvolvimento infantil para promover cuidados mais efetivos, eles relataram que muitas das vezes em atendimento com outros profissionais da saúde, não são estimulados a explanar sobre suas dúvidas, no que conferem as habilidades 
alcançadas em cada etapa do desenvolvimento infantil.

Passaram a observar que as abordagens são diferenciadas nos serviços, ao ampliar suas percepções em relação à extensão dos aspectos que envolvem o desenvolvimento, não se prendendo mais somente a aspectos biológicos como influenciadores desse processo:

"Sei que aqui o atendimento é diferente de lá do posto, aqui eles vejam outras coisas, fazem outras perguntas, conversam mais com a gente" (Jade).

Eles passam a atribuir novos significados nos cuidados prestados aos seus filhos dentro da própria dinâmica familiar. Percebem a incorporação das transformações que o serviço causa no ambiente familiar, bem como, nas mudanças de comportamento deles frentes aos cuidados com seus filhos:

"Tive dificuldades com a outra filha, não tinha informações de como estimular ela. Com essa não, recebo informações aqui e tento fazer tudo com ela em casa pra ela ficar mais desenvolvida. Com a mais velha eu não tinha a mínima ideia de como fazer as estimulações, não fui orientada" (Gramada).

Como se percebe, no relato da participante a seguir, que ao constatar a progressão do seu filho, aflora sentimentos de satisfação, ocasionando cada vez mais estímulos para fortalecer o vínculo com o serviço de vigilância do desenvolvimento infantil:

"Quando venho aqui eles sempre explicam o que ele tá fazendo de novo. Cada mês é uma conquista, é um detalhe novo que ele tá fazendo. Fico feliz! E cada vez quero vir aqui pra conversar sobre as conquistas dele" (Esmeralda).

\section{As repercussões dos atendimentos no} cotidiano dos pais

Quando os pais estão bem orientados, eles se tornam um agente facilitador em promover o desenvolvimento integral da criança. Eles estabelecem novas rotinas em seu ambiente para favorecer essa ação. Que muitas das vezes devido ausência de informações adequadas não estavam desenvolvendo cuidados necessários à infância:

"Deixava ela a maioria do tempo na rede, sem nenhum brinquedo, sem nada. Ela conversou comigo e disse o que poderia fazer pra estimular. Hoje já coloco minha bebê pra ver as coisas, coloco no chão, coloco brinquedos” (Pérola).

A estimulação possibilita à criança desenvolver-se em todo o seu potencial de acordo com a fase em que se encontra. A criança precisa ser constantemente estimulada e a família deve estar constantemente atenta para o seu papel de fornecedora desses estímulos:

“Coloco em prática todas as orientações. Ela sempre está na frente. Agora recebo orientações para estimular a fala dela" (Jade).

\footnotetext{
"Recebi orientações que fui fazendo em casa e hoje ela já tem força no pescocinho" (Pérola).

"Ela estava ficando muito na ponta do pé. Eles avaliaram, perguntaram se usava anda já. Disse que sim, pois não sabia que poderia fazer mal. Às vezes colocava ela, pois não tinha ninguém para segurar, enquanto eu estava fazendo as coisas de casa. Mas agora parei de usar" (Amazonita).
} 
Como se constatou através do relato da mãe mencionado acima, após receber uma orientação, houve mudança de comportamento. A genitora deixou de usar no seu cotidiano um recurso que poderia vir a ser prejudicial ao desenvolvimento da criança:

"Isso de estímulos a gente pensa que é mais com a escola, mas depois que vir aqui passei a conversar mais com ela, dizer o nome das coisas, a contar histórias infantis" (Pérola).

"Eles me informam sobre os brinquedos não adequados para a idade dele e também me falaram sobre o anda já” (Gramada).

"Aqui eles me informam sobre os estímulos que posso oferecer de acordo com a idade dele, os cuidados que devo ter com os brinquedos pequenos" (Jade).

\section{Significados e dificuldades atribuídos} ao serviço de vigilância do Desenvolvimento Infantil no NASF Águas Lindas

Por ser um dos serviços essenciais ao acompanhamento do desenvolvimento infantil, esperava-se que a oferta e a dinâmica de funcionamento do serviço fossem de conhecimento da população adstrita no território do NASF Águas Lindas. Mas um achado unânime na pesquisa revela ausência de experiências anteriores com serviços de vigilância:

"Não sabia como funcionava aqui. Pensei que era só palestra e nem sabia que podia vir sem está doente" (Gramada).
"Imaginei que seria só uma consulta normal" (Turquesa).

"Não imaginei que era assim. Imaginei que era pra ver o peso, mas foi um pouco mais" (Amazonita).

"Pensei que seria só uma vez, quando vi que era acompanhamento, gostei! “ (Âmbar).

"Inicialmente não sabia o que era, marquei por curiosidade" (Ônix).

É importante destacar que todos os participantes da amostra da pesquisa, ainda que não tenha sido intencional, foram compostos por pais advindos de encaminhamentos realizados no momento em que estavam utilizando outro serviço do NASF "Sala de Espera do Teste do Olhinho". Não foram encontrados na amostra usuários encaminhados por outros profissionais que compõe o NASF e das ESF e, atualmente, o NASF de Águas Lindas cobre 5 (cinco) ESF, representando um quantitativo elevado de profissionais que poderia realizar a articulação com o serviço, o que infelizmente, não vem ocorrendo:

\footnotetext{
"Fiquei sabendo daqui quando vir fazer o teste do olhinho dele. O pessoal informou que eu poderia agendar um dia e voltar aqui com ele" (Esmeralda).
}

Ao verificar a resposta dos participantes da amostra ao questionário sociodemográfico que compõe o instrumento da pesquisa, notou- 
se a ausência de visitas dos ACS nas residências e apenas uma das participantes relatou receber visita do Agente Comunitário de Endemia (ACE). Ao questionar sobre a localização das residências, apenas 4 (quatro) participantes moravam na aérea de abrangência da cobertura das ESF que apoiam o NASF. Esse é um ponto importante a ser investigado, pois supõe-se que os usuários do serviço de desenvolvimento infantil do NASF Águas Lindas não são oriundos do território de abrangência e esse pode ser uma das justificativas a ausência de visitas dos ACS e que as RAS não ocorrem em todas as localidades do município de Ananindeua:

"Acredito que aqui tem um grande diferencial. Não é em todo bairro que tem um serviço desse de atendimento para crianças" (Esmeralda).

Trazendo assim dificuldades no que confere ao deslocamento até o serviço, ocasionando limitação ao acesso, o que não deveria existir, visto que é preconizado o atendimento adstrito no território do usuário:

"A única dificuldade que apresento com o serviço é a de locomoção, pois dependo do horário de ônibus para chegar até aqui e se torna cansativo. E às vezes chego atrasada" (Turqueza).

Os usuários do serviço são os atores principais para compartilhar suas impressões acerca dos atendimentos, bem como sensibilizar os outros usuários sobre a importância do serviço por meio do compartilhar da sua experiência com outros usuários, viabilizando maior cobertura a quem desconhece o serviço ofertado à comunidade:

"Vi que o atendimento aqui é diferente, mas detalhado, fazem mais perguntas. Como minha irmã tem uma filha da idade da minha, eu falei para ela trazer a minha sobrinha aqui para consultar também e hoje somos nós duas em atendimento aqui" ('Topázio).

É ao avaliar o serviço sob a ótica do usuário que se obtém informações pertinentes referente ao serviço, à organização, à estrutura, ao campo relacional, além de viabilizar aos profissionais uma reflexão sobre as práticas que utilizam no serviço:

"Aqui eles são bem atenciosos, perguntam todos os detalhes, são pacientes nas informações. Aqui a gente aprende coisas que nem sabia. Sempre faço questão de vir aqui, quando falto, faço de tudo para remarcar” (Onix).

"Fiz questão de continuar aqui, pois eles avisaram que o atendimento seria mensal e se tivesse alguma anormalidade com ele, seria encaminhado para outro serviço para fazer tratamento" (Esmeralda).

\section{DISCUSSÃO}

As mães perceberam que as orientações auxiliaram na promoção do desenvolvimento dos seus filhos, assim como o seu papel de estimuladora nesse processo, aumentando a proteção e atribuindo um novo significado ao cuidado com seus filhos. Além disso, notaram que possuem dúvidas sobre os cuidados cotidianos e algumas comparavam o desenvolvimento de seus filhos com os filhos de outros familiares e amigos, gerando sentimento de angústia quando notavam 
alguma diferença considerada negativa para elas.

Nesse sentindo, o desenvolvimento infantil é um reflexo das condições familiares somadas a assistência recebida dos serviços de saúde. Promovê-lo é fundamental pra gerar um indivíduo autônomo que cuide de si e de outrem, o que gera benefícios pra população e pro controle das políticas de saúde ${ }^{6}$.

Em relação à saúde da criança, o contexto familiar e a família são sujeitos de atenção. Assim, estender atenção ao ambiente domiciliar é importante pois amplia a percepção de problemas, saindo apenas dos biológicos e chegando aos psicológicos e sociais, o que fortalece o vínculo entre família e cuidadores ${ }^{7}$.

Soma-se a isso a apropriação da Carteira de Saúde da Criança (CSC), que implica na construção de um cuidado em que todos os membros da equipe de saúde e a família são autores importantes8. A CSC é utilizada como instrumento de orientação às mães para a saúde da criança e de avaliação do desenvolvimento?.

Também são verificados em outros estudos que algumas falhas de orientação geram inseguranças nas mães. Como a ausência de orientações sobre estimulação da criança ou sobre uso de recreações e brincadeiras que promovam o desenvolvimento infantil ${ }^{9}$.

Sabe-se que a construção de vínculos seguros para a criança necessita de cuidadores que ajam de forma responsiva, confortadora e acolhedora. Conforme o desenvolvimento infantil ocorre, espera-se que os cuidadores criem uma base segura, gerando confiança e tolerância à frustração. Além disso, o desenvolvimento infantil saudável depende de os cuidadores desenvolverem uma comunicação efetiva e reconhecerem a criança como ser ativo e atuante nas suas interações. Caso o cuidador não se disponha a atender as necessidades da criança ou não as reconhecer, podem-se desencadear vínculos frágeis e problemas emocionais, comportamentais ou cognitivos futuros ${ }^{10}$.

Outrosfatores percebidos pelasmães foram a existência de uma diferença entre crescimento e desenvolvimento infantil e os amplos aspectos que envolvem o desenvolvimento. Em relação ao serviço de vigilância do desenvolvimento, as mães perceberam os objetivos desse serviço e as consequências positivas geradas em seus comportamentos e no ambiente familiar. Notaram que não há orientações sobre o desenvolvimento infantil em outros serviços e perceberam que as orientações tornam os serviços melhores, levando esse raciocínio para os outros serviços. Ademais, aumentaram o vínculo com o serviço conforme perceberam os resultados progressivos.

Segundo estudos, os profissionais de saúde têm a responsabilidade com as orientações familiares, afim de ajudarem na compreensão do processo de desenvolvimento por meio de compartilhamento de informações, de apresentação de alternativas ao atendimento e realização da vigilância do desenvolvimento da criança. Além disso, são capacitados para fazer intervenções com mães e pais, pois disseminam 
conhecimentos e favorecem a compreensão das necessidades da criança para um desenvolvimento correto, além de ensinar mecanismos para a criação de vínculo da criança com a família. Essas intervenções são positivas pois resultam em boa alimentação da criança e geram apego, aprendizagem, estabelecimento de limites e construção de autonomia ${ }^{10}$.

Sobre o fato de outros serviços serem frágeis em orientações sobre a saúde da criança, verificou-se em estudos que há fragilidade na prática dos enfermeiros, levando a não avaliação do desenvolvimento psicomotor, em alguns casos, por ausência de conhecimento na área ${ }^{11}$. Ademais, os funcionários do serviço de saúde não têm conhecimento do desenvolvimento da linguagem, sendo que ações em conjunto com os fonoaudiólogos seriam de fundamental importância para o desenvolvimento infantil ${ }^{12}$.

Do ponto de vista dos pacientes, a satisfação com o serviço de saúde está associada com a resolução do problema que motivou a consulta ${ }^{13,14}$. Assim como o atendimento humanizado é um indicador de qualidade, pois o usuário que não se sente acolhido e ouvido, avalia mal o serviço ${ }^{13}$. Contudo, estudos mostram que a avaliação e a vigilância do desenvolvimento são feitas apenas com a percepção materna, sem testar a presença no exame da criança ${ }^{9}$, sendo necessário sempre investigar a qualidade do serviço oferecido mesmo com devolutivas maternas positivas. Além disso, o tempo destinado às consultas de saúde infantil são entre cinco e dez minutos, as vezes mais de dez minutos, muito abaixo do tempo de duração estabelecido como ideal ${ }^{15}$.

As mães também alegaram desconhecer o serviço por falta de articulação entre os funcionários no uso do serviço. Observaram que as dificuldades no deslocamento influenciam negativamente no acesso ao serviço. Além disso, evidenciou-se que elas são as divulgadoras do serviço na comunidade e que suas avaliações demonstram a qualidade do funcionamento do serviço oferecido.

Assim, são verificados em outros estudo a existência de falhas de outros serviços como falta de acesso e morosidade na atenção às crianças, ausência de vínculo desencadeado pelo desinteresse e não responsabilização, carência da integralidade e falta de organização dos serviços pela privação da coordenação ${ }^{16}$.

Ademais, ainda que existam obstáculos para alcançar a atenção à saúde, os profissionais que oferecem atenção, diálogo e acolhimento aos usuários recebem avaliações positivas do atendimento, sendo sugerido maior corresponsabilização dos profissionais em facilitar o acesso, acolhendo a todos e priorizando aqueles usuários com casos não urgentes mas que buscam com frequência os serviços ${ }^{13}$.

\section{CONCLUSÃO}

A produção desta pesquisa ofereceu informações essenciais sob a ótica dos usuários 
acerca do serviço que vem sendo realizado no NASF Águas Lindas. Diante das percepções verificou-se a amplitude que o serviço tem alcançado nos cuidados à primeira infância. Ao entrelaçar os usuários, representado pelos pais e crianças, ao serviço de atenção primária, busca-se estimulá-los a buscarem por maior envolvimento nas políticas públicas resultando assim em um usuário mais autônomo no processo saúde.

O serviço tem alcançado resultados positivos com os pais, como representado por um dos achados da pesquisa, a ampliação do conceito de saúde além dos aspectos fisiológicos, envolvendo o contexto familiar, social, entre outros. Constataram-se novos hábitos incorporados na rotina familiar, após sua adesão ao serviço, como por exemplo, a utilização do serviço de saúde não somente para o tratamento, mas também para a prevenção. E a partir dessas ações que a população vai incorporando novas práticas na utilização dos serviços de saúde.

É interessante notar que ao oferecer ao usuário a oportunidade para avaliar o serviço, possibilita-se também ampliar o debate de questões inerentes ao serviço que vão além de aspectos estruturais e relacionais. $\mathrm{Na}$ amostra conheceram-se dificuldades que ultrapassam essas dimensões e que estão relacionadas ao nível de gestão municipal. E pelos resultados positivos alcançados, sugere-se a gestão realizar alguns ajustes para promover melhorias no serviço e ampliar a participação dos usuários.

Atualmente o serviço é realizado exclusivamente por profissionais em formação, onde ocorre constante rotatividade, que condiciona um entrave para criação, fortalecimento e manutenção do vínculo usuário e profissional. Então, sugere-se alocar um profissional do quadro funcional do NASF para ser o técnico de referência do serviço, assim, o contato com o usuário será constante e terá, consequentemente, ganhos no vínculo usuárioserviço. Por meio da pesquisa, apurou-se que os encaminhamentos para o serviço não têm sido realizados pelos profissionais atuantes no NASF, ESF, e nas UBS do território de abrangência. É importante que os profissionais juntamente com a gestão de saúde busquem articular as diretrizes políticas e as práticas de saúde, procurando a possibilidade de promover a ampliação do fluxo do serviço vindo desses pontos de atenção à saúde,

Sugere-se que ocorra um processo contínuo de qualificação com as equipes, a fim de disseminar essa prática tão relevante e apresentar o serviço, os objetivos, a dinâmica de funcionamento, potencializando, assim, o aumento dos níveis de integração nas redes de assistência à saúde, bem como o favorecimento de maior comunicação entre as equipes multiprofissionais. Embora as dificuldades no cotidiano sejam inúmeras, visto que muitas lacunas persistem e dificultam as estratégias de melhoria no serviço de vigilância, ressalta-se que o objetivo do serviço tem sido alcançados e tem sido transformador no que confere a assistência à saúde da criança. 


\section{REFERÊNCIAS}

1. Ministério da Saúde. PORTARIA No 1.130 [Internet]. 2015 [cited 2020 Apr 22];Available from: https://bvsms.saude.gov.br/bvs/saudelegis/gm/2015/ prt1130_05_08_2015.html

2. Ministério da Saúde. Caderneta de Saúde da Criança [Internet]. 2015 [cited 2020 Apr 22];Available from: www.saude.gov.br

3. Ministério da Saúde. CADERNO DE ATENÇÃO BÁSICA 33. 2012;

4. Damasceno SS, Nóbrega VM da, Coutinho SED, Reichert AP da S, Toso BRG de O, Collet N. Saúde da criança no Brasil: orientação da rede básica à Atenção Primária à Saúde. Cien. Saude Colet. [Internet]. 2016 Sep 1 [cited 2020 Apr 22];21(9):2961-2973. Available from: http://www.scielo.br/scielo.php?script=sci_ arttext\&pid=S1413-81232016000902961\&lng=pt\&tlng $=\mathrm{pt}$

5. $\quad$ Bardin L. Análise do Conteúdo. 2011.

6. Silva ÂCD da, Engstron EM, Miranda CT de. Fatores associados ao desenvolvimento neuropsicomotor em crianças de 6-18 meses de vida inseridas em creches públicas do Município de João Pessoa, Paraíba, Brasil. Cad. Saude Publica. 2015 Jan 1;31(9):1881-1893.

7. Araújo R de L, Mendonça AVM, Sousa MF de. Percepção dos usuários e profissionais de saúde no Distrito Federal: os atributos da atenção primária. Saúde em Debate [Internet]. 2015 Jun [cited 2020 Apr 22];39(105):387-399. Available from: http://www. scielo.br/scielo.php? script $=$ sci_arttext\&pid $=$ S0103$11042015000200387 \& \operatorname{lng}=$ pt\&tlng=pt

8. Ramos JFC, Miranda L, Peixoto MVM, Marques MR, Mendes LC, Pereira EHP. Participative research and comprehensive child healthcare promotion strategies in the Brazilian National Health System (SUS). Interface Commun. Heal. Educ. 2018 Oct 1;22(67):1077-1089.

9. Munhoz Gaiva MA, Coutinho Monteschio C, Souza Moreira M, Marques Salge A. Avaliação do crescimento e desenvolvimento infantil na consulta de enfermagem. Av. en Enfermería. 2018 Jan 1;36(1):9-21. 10. Comitê Científico do Núcleo Ciência Pela Infância. IMPORTÂNCIA DOS VÍNCULOS FAMILIARES NA PRIMEIRA INFÂNCIA: ESTUDO II [Internet]. 1a. São Paulo: Fundação Maria Cecília Souto Vidigal - FMCSV; 2016 [cited 2020 Apr 22]. Available from: www.ncpi.org.br

11. Reichert AP da S, Collet N, Eickmann SH, Lima M de C. Vigilância do desenvolvimento infantil: Estudo de intervenção com enfermeiros da Estratégia Saúde da Família. Rev. Lat. Am. Enfermagem. 2015 Sep 1;23(5):954-962.

12. Pizolato RA, Fonseca LMM, Bastos R da S, Fernandes AY, Lefévre F, Maximino LP. Vigilância do desenvolvimento da linguagem da criança: conhecimentos e práticas de profissionais da atenção básica à saúde. Rev. CEFAC. 2016 Oct;18(5):1109-1120. 13. Gomide MFS, Pinto IC, Bulgarelli AF, Santos ALP Dos, Pilar Serrano Gallardo M Del. A satisfação do usuário com a atenção primária á saúde: uma análise do acesso e acolhimento. Interface Commun. Heal. Educ. 2018 Apr 1;22(65):387-398.

14. Halal IS, Sparrenberger F, Bertoni AM, Ciacomet C, Seibel CE, Lahude FM, et al. Avaliação da qualidade de assistência primária à saúde em localidade urbana da região sul do Brasil. Rev. Saude Publica. 1994 Apr;28(2):131-136.

15. Maia AR, Fernades J, Leite MF, Santos H, Pereira SA. Avaliação do desenvolvimento psicomotor pelos médicos de família: estudo observacional. Rev Port Med Geral Fam [Internet]. 2016 [cited 2020 Apr 19];32( 4 ): 248-256. Available from: http://www.scielo. mec.pt/scielo.php? script $=$ sci_arttext\&pid $=$ S2182$51732016000400004 \&$ lang $=\mathrm{pt}$

16. Silva RMM Da, Viera CS, Oliveira Toso BRG De, Neves ET, Rodrigues RM. Problem-solving capacity in children health care: The perception of parents and caregivers. ACTA Paul. Enferm. 2013;26(4):382-388.

OBSERVAÇÃO: Os autores declaram não existir conflitos de interesse de qualquer natureza. 